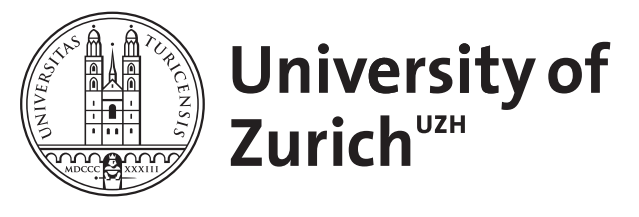

\title{
Risk without return
}

Goldberg, Lisa R. ; Mahmoud, Ola

\begin{abstract}
Risk-only investment strategies have been growing in popularity as traditional investment strategies have fallen short of return targets over the last decade. However, risk-based investors should be aware of four things. First, theoretical considerations and empirical studies show that apparently dictinct risk-based investment strategies are manifestations of a single effect. Second, turnover and associated transaction costs can be a substantial drag on return. Third, capital diversification benefits may be reduced. Fourth, there is an apparent connection between performance and risk diversification. To analyze risk diversification benefits in a consistent way, we introduce the Risk Diversification Index (RDI) which measures risk concentrations and complements the Herfindahl-Herschman Index (HHI) for capital concentrations.
\end{abstract}

DOI: https://doi.org/10.21314/JOIS.2013.018

Posted at the Zurich Open Repository and Archive, University of Zurich

ZORA URL: https://doi.org/10.5167/uzh-162946

Journal Article

Published Version

Originally published at:

Goldberg, Lisa R.; Mahmoud, Ola (2013). Risk without return. The Journal of Investment Strategies, 2(2):111-120.

DOI: https://doi.org/10.21314/JOIS.2013.018 


\title{
Risk without return
}

\section{Lisa R. Goldberg}

Department of Statistics, University of California, Berkeley, CA 94720-3880, USA; email: Irg@stat.berkeley.edu

\section{Ola Mahmoud}

Pictet Wealth Management, 60 Route des Acacias, CH-1211 Geneva 73, Switzerland; email: omahmoud@pictet.com

and

Coleman Fung Risk Management Research Center, University of California, Berkeley, CA 94720-3880, USA

(Received January 20, 2013; accepted January 31, 2013)

\begin{abstract}
Risk-only investment strategies have been growing in popularity as traditional investment strategies have fallen short of return targets over the last decade. However, risk-based investors should be aware of four things. First, theoretical considerations and empirical studies show that apparently distinct risk-based investment strategies are manifestations of a single effect. Second, turnover and associated transaction costs can be a substantial drag on return. Third, capital diversification benefits may be reduced. Fourth, there is an apparent connection between performance and risk diversification. To analyze risk diversification benefits consistently, we introduce the risk diversification index, which measures risk concentrations and complements the Herfindahl-Hirschman index for capital concentrations.
\end{abstract}

\section{INTRODUCTION}

In an inverted caricature of pre-Markowitz investing, some funds allocate assets strictly on the basis of risk and without regard for expected return. Strategies based on minimum variance, beta and risk parity have been growing, in both popularity and assets under management, as traditional investment approaches have fallen short of return targets over the last decade. Risk-only strategies are not a new idea. Markowitz (1952) identified the minimum variance portfolio as optimal for a mean-variance investor whose estimates of asset expected returns are all equal.

This research was supported by the Coleman Fung Risk Management Research Center at University of California, Berkeley. We are grateful to Bob Anderson, Stephen Bianchi and Michael Hayes for their contributions to this paper. 


\section{RISK WITH RETURN}

The capital asset pricing model (CAPM) predicts a linear relationship between the expected excess return of a portfolio and its market beta. However, empirical studies show that this simple relationship is incorrect. In a seminal paper, Black et al (1972) documented the first CAPM anomaly: by the standards of the CAPM, the risk-adjusted returns of high-beta equities are too low and those of low-beta equities are too high. Two decades later, Fama and French (1992) found that the size and value factors add to the explanation of stock return provided by market beta. The Fama-French threefactor model is, by far, the most well-established CAPM alternative. As in the case of the low-beta anomaly, there is disagreement about the underlying drivers of size and value effects, and there are contributions to the literature from both behavioral and neoclassical finance. In a survey of the vast empirical literature on the CAPM, Fama and French (2004) commented that

the conflict between the behavioral irrational pricing story and the rational risk story for the empirical failures of the CAPM leave us at a timeworn impasse.

However, there may be a connection between risk-based investing and the expectedreturn-based Fama-French model. Scherer (2011) regressed the returns of a minimum variance portfolio onto the size and value factors. He found that:

$83 \%$ of the variation of the minimum variance portfolio excess returns (relative to a CAPM alternative) can be attributed to the Fama-French factor: investors can achieve a higher Sharpe ratio than the minimum variance portfolio by directly identifying the risk based pricing anomalies that the minimum variance portfolio draws upon.

He also makes the provocative comment:

In this author's view, the minimization of risk is - on its own - a meaningless objective.

To what extent does recent data support this remark? Through a study of three popular risk-only strategies, we will show that risk-only can be a meaningful investment approach, outperforming equally weighted and balanced portfolios in terms of return and risk diversification.

\section{RISK-ONLY STRATEGIES}

For the period from January 1988 to December 2010, we evaluate three popular riskonly strategies (minimum variance, risk parity and low beta) based on four asset classes (US equity, US treasury bonds, US investment grade corporate bonds and 
TABLE 1 Summary statistics for the balanced, equally weighted and risk-based strategies over the period January 1988-December 2010.

\begin{tabular}{lccccc}
\hline & $\begin{array}{c}\text { Annualized } \\
\text { returns (\%) }\end{array}$ & $\begin{array}{c}\text { Annualized } \\
\text { volatility (\%) }\end{array}$ & $\begin{array}{c}\text { Sharpe } \\
\text { ratio }\end{array}$ & Skewness & Kurtosis \\
\hline Balanced & 9.5 & 10.3 & 0.92 & -0.93 & 2.87 \\
Equal-weighted & 8.7 & 7.5 & 1.17 & -0.89 & 5.10 \\
Risk parity & 9.0 & 5.6 & 1.63 & -0.69 & 3.06 \\
Minimum variance & 8.4 & 5.4 & 1.57 & -0.47 & 3.31 \\
Low beta & 8.3 & 6.8 & 1.23 & 0.17 & 1.75 \\
\hline
\end{tabular}

commodities). ${ }^{1}$ In the minimum variance strategy, an asset's weight is proportional to the sum of its covariances with other assets:

$$
\omega_{i} \propto \sum_{j} \sigma_{i j}
$$

In the risk parity strategy, assets are weighted so their ex post risk contributions are equal. An asset's weight in the low-beta strategy is inversely proportional to its benchmark beta. All strategies are fully invested and long only. Asset weights in these strategies depend on variance and covariance estimates, which are calculated using a thirty-six-month rolling window of trailing returns. Varying the estimation methodology by changing the length of the rolling window or the weighting scheme applied to the returns within this window does not substantially alter our results. All strategies are rebalanced monthly.

We also consider an equally weighted portfolio and our benchmark: a balanced portfolio of our four asset classes. With the traditional 60/40 balanced allocation in mind, we chose 60/20/10/10 weights for equities, commodities, corporate bonds and treasuries.

Table 1 displays performance statistics on all strategies. Our benchmark has the highest annualized returns but also the highest volatility. From the perspective of risk and risk-adjusted returns, all three risk-only strategies beat the benchmark and the equal-weighted portfolio. Among the risk-based strategies, risk parity outperforms its rival minimum variance and low-beta portfolios in terms of both return and Sharpe ratio.

\footnotetext{
${ }^{1}$ All four asset class time series are obtained from the Global Financial Data database (www.global financialdata.com). We took the Russell 3000 Total Return Index, the USA 10-Year Government Bond Total Return Index, the USA Total Return AAA Corporate Bond Index and the Goldman Sachs Commodity Price Index to represent US equities, US treasuries, US investment grade corporate bonds and commodities, respectively.
} 
FIGURE 1 Cumulative return to the balanced, equally weighted and risk-based strategies over the period January 1988-December 2010.

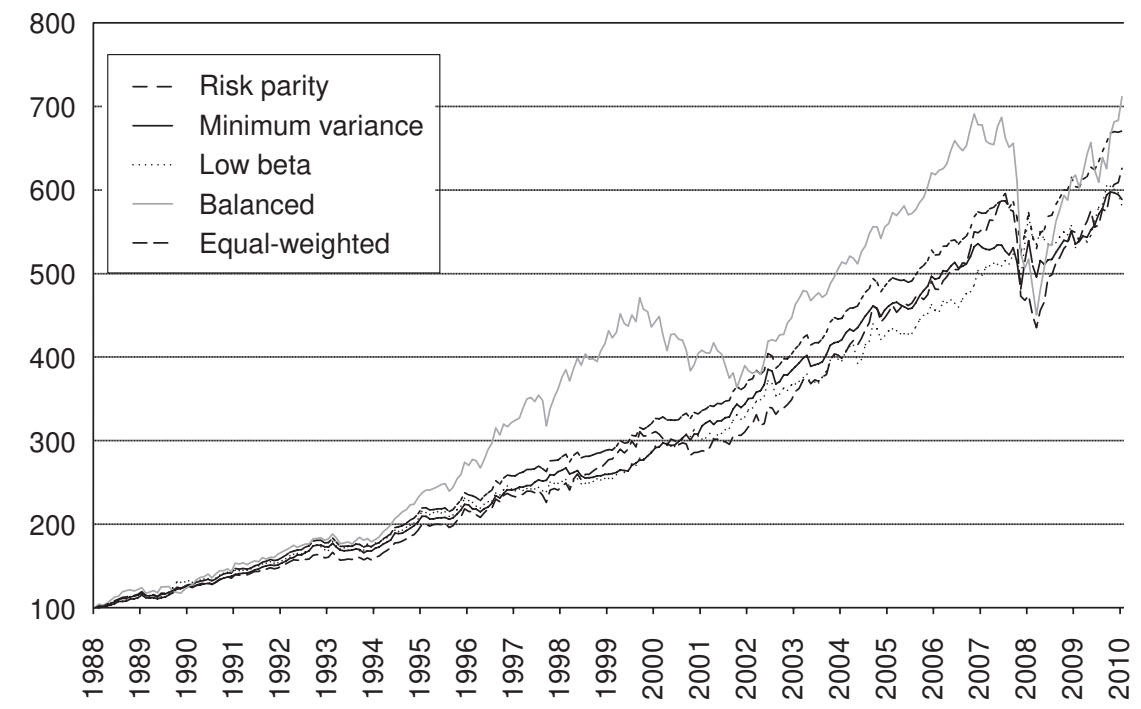

TABLE 2 Correlations between the balanced, equally weighted and risk-based strategies over the period January 1988-December 2010.

\begin{tabular}{lccccc}
\hline & $\begin{array}{c}\text { Risk } \\
\text { parity }\end{array}$ & $\begin{array}{c}\text { Minimum } \\
\text { variance }\end{array}$ & $\begin{array}{c}\text { Low } \\
\text { beta }\end{array}$ & Balanced & $\begin{array}{c}\text { Equal- } \\
\text { weighted }\end{array}$ \\
\hline Risk parity & 1.00 & 0.91 & 0.89 & 0.68 & 0.86 \\
Minimum variance & - & 1.00 & 0.87 & 0.46 & 0.65 \\
Low beta & - & - & 1.00 & 0.26 & 0.57 \\
Balanced & - & - & - & 1.00 & 0.81 \\
Equal-weighted & - & - & - & - & 1.00 \\
\hline
\end{tabular}

\section{VARIATIONS ON A THEME}

Some of the common elements of risk-based investment strategies are elucidated in Clarke et al (2011), who provided a reexpression of (3.1) in a market with a single risk factor:

$$
\omega_{n} \propto \frac{1}{\sigma_{\epsilon n}^{2}}\left(1-\frac{\beta_{n}}{\beta}\right)
$$

Formula (4.1) shows that the weight of asset $n$ decreases as either its CAPM market model beta, $\beta_{n}$, or its idiosyncratic variance, $\sigma_{\epsilon i}^{2}$, increases. Furthermore, 
FIGURE 2 Monthly turnover for the risk-based strategies over the period January 1988December 2010.

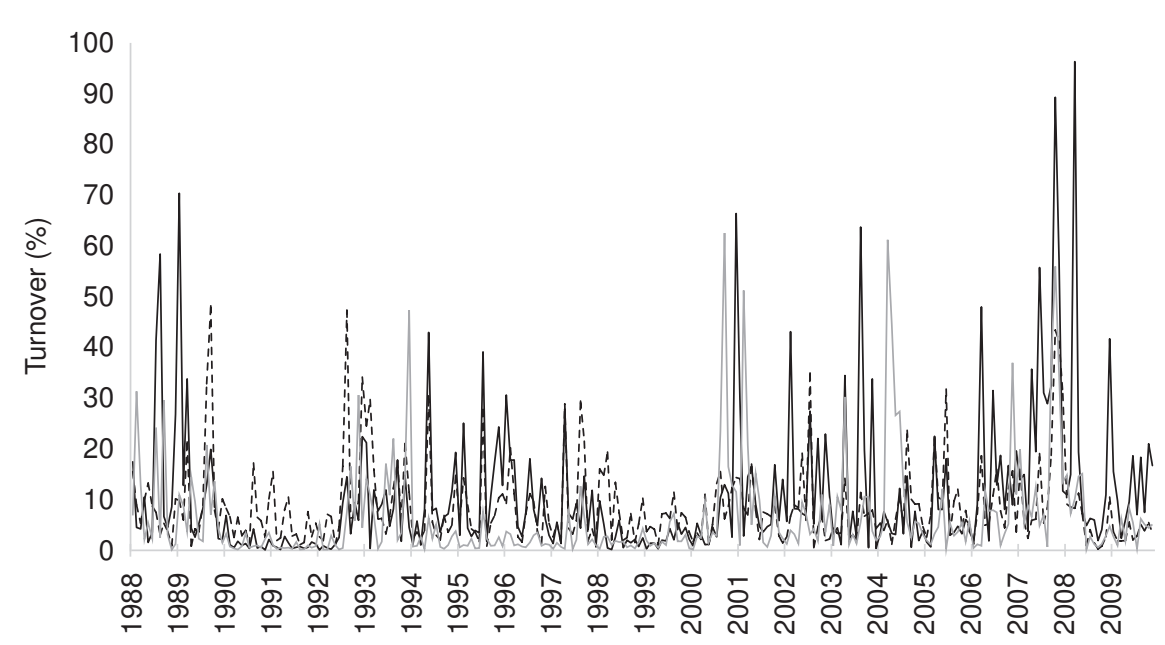

if $\beta_{n}$ exceeds a threshold $\beta$, the weight of asset $n$ in the minimum variance portfolio is negative. Formula (4.1) suggests that portfolios emphasizing minimum-variance, low-beta assets or assets with low volatility may be correlated.

The performance of our three risk-only strategies over the period January 1988December 2010 provides empirical support for this hypothesis. Figure 1 on the facing page shows cumulative returns to the three low-risk strategies and the balanced portfolio. We observe comovement across the low-risk strategies, with risk parity outperforming the others. Note that the benchmark has the highest return over the twenty-two-year window; however, it is also the most volatile strategy and it has the lowest Sharpe ratio. The correlations between strategies range from 0.87 to 0.95 , as shown in Table 2 on the facing page.

\section{THE IMPACT OF TURNOVER}

We evaluate the drag on return caused by turnover-induced transaction costs. Portfolio turnover from month to month is the lower of the total amount of assets sold and bought. Figure 2 shows this value over the twenty-two-year period for each of the three risk-based portfolios. The average turnover is highest for minimum variance, followed closely by low beta and then by risk parity. We observe that turnover is 
typically less than $10 \%$ during bull markets, but often exceeds $50 \%$ during turbulent market periods. This implies potential large, rebalancing-induced trading costs in bull markets. Determining the precise relationship between turnover and its induced cost is beyond the scope of this paper, so we simulate. We assume that turnover incurs a penalty in the form of a cost of 10 basis points on the lower end and 50 basis points on the higher end, multiplied by the turnover. Summary statistics for the risk-based strategies and the benchmarks incorporating turnover-induced trading costs are shown in Table 3 on the facing page. While the risk profile does not change substantially, cost diminishes returns and Sharpe ratios, and the effect is more severe for the risk-only strategies. $^{2}$

\section{CONCENTRATION RISK}

Low-risk strategies naturally concentrate on defensive assets. The summary statistics in Table 4 on page 118 confirm that fixed income instruments have lower volatilities than equities and commodities. Figure 3 on page 118 shows that, in all three strategies, the largest allocation is to US corporate bonds, followed by US treasuries. Each strategy allocates at least $70 \%$ of its capital to fixed income.

A standard measure of concentration risk is the normalized Herfindahl-Hirschman index (HHI):

$$
\mathrm{HHI}=\frac{\left(\sum_{n=1}^{N} w_{n}^{2}\right)-1 / N}{1-1 / N},
$$

where $N$ is the number of assets in the portfolio and $w_{n}$ is the weight of asset $n$. The values of HHI range from 0 for an equally weighted portfolio to 1 for a portfolio composed of a single asset.

For the balanced portfolio, HHI $=0.7$ due to the $60 \%$ allocation to equities. Among our risk-only strategies, minimum variance has the highest concentration risk, $\mathrm{HHI}=0.6$, followed by low beta, $\mathrm{HHI}=0.3$. This relatively high concentration risk can be explained by the fixed income allocations. Given the average weights of risk parity which are shown in Figure 3, it may seem puzzling that this portfolio turns out to be almost perfectly diversified with an HHI of 0.08 . Rather than lowering the overall risk, risk parity equalizes the contributions of assets to overall portfolio risk. In the example we considered, the act of equalizing risk contributions served to approximately equalize capital contributions.

Inspired by the HHI, the parallel between capital and risk allocations suggests a simple measure of risk diversification. It is natural to measure risk diversification in

\footnotetext{
${ }^{2}$ The risk-only strategies that we consider are fully invested. In practice, however, some risk-only strategies are levered. Anderson et al (2012) show that financing costs can negate the outperformance of a levered risk parity strategy.
} 
TABLE 3 Summary statistics for the balanced, equally weighted and risk-based strategies with and without accounting for turnover-induced transaction costs over the period January 1988-December 2010.

(a) Balanced

\begin{tabular}{lccccc}
\hline & $\begin{array}{c}\text { Annualized } \\
\text { returns (\%) }\end{array}$ & $\begin{array}{c}\text { Annualized } \\
\text { volatility (\%) }\end{array}$ & $\begin{array}{c}\text { Sharpe } \\
\text { ratio }\end{array}$ & Skewness & Kurtosis \\
\hline No cost & 9.5 & 10.3 & 0.92 & -0.93 & 2.87 \\
Low cost & 9.1 & 10.0 & 0.91 & -0.9 & 2.88 \\
High cost & 8.5 & 9.7 & 0.88 & -0.92 & 2.95 \\
\hline
\end{tabular}

(b) Equal-weighted

\begin{tabular}{lccccc}
\hline & $\begin{array}{c}\text { Annualized } \\
\text { returns (\%) }\end{array}$ & $\begin{array}{c}\text { Annualized } \\
\text { volatility (\%) }\end{array}$ & $\begin{array}{c}\text { Sharpe } \\
\text { ratio }\end{array}$ & Skewness & Kurtosis \\
\hline No cost & 8.7 & 7.5 & 1.17 & -0.89 & 5.10 \\
Low cost & 8.5 & 7.3 & 1.16 & -0.91 & 5.01 \\
High cost & 7.9 & 7.2 & 1.10 & -0.9 & 5.24 \\
\hline
\end{tabular}

(c) Risk parity

\begin{tabular}{lccccc}
\hline & $\begin{array}{c}\text { Annualized } \\
\text { returns (\%) }\end{array}$ & $\begin{array}{c}\text { Annualized } \\
\text { volatility (\%) }\end{array}$ & $\begin{array}{c}\text { Sharpe } \\
\text { ratio }\end{array}$ & Skewness & Kurtosis \\
\hline No cost & 9.0 & 5.6 & 1.63 & -0.69 & 3.06 \\
Low cost & 8.8 & 5.6 & 1.57 & -0.65 & 3.01 \\
High cost & 8.1 & 5.9 & 1.37 & -0.66 & 3.11 \\
\hline
\end{tabular}

(d) Minimum variance

\begin{tabular}{lccccc}
\hline & $\begin{array}{c}\text { Annualized } \\
\text { returns (\%) }\end{array}$ & $\begin{array}{c}\text { Annualized } \\
\text { volatility (\%) }\end{array}$ & $\begin{array}{c}\text { Sharpe } \\
\text { ratio }\end{array}$ & Skewness & Kurtosis \\
\hline No cost & 8.4 & 5.4 & 1.57 & -0.47 & 3.31 \\
Low cost & 7.7 & 6.1 & 1.26 & -0.67 & 3.94 \\
High cost & 7.1 & 6.2 & 1.15 & -0.65 & 3.99 \\
\hline
\end{tabular}

(e) Low beta

\begin{tabular}{lccccc}
\hline & $\begin{array}{c}\text { Annualized } \\
\text { returns (\%) }\end{array}$ & $\begin{array}{c}\text { Annualized } \\
\text { volatility (\%) }\end{array}$ & $\begin{array}{c}\text { Sharpe } \\
\text { ratio }\end{array}$ & Skewness & Kurtosis \\
\hline No cost & 8.3 & 6.8 & 1.23 & 0.17 & 1.75 \\
Low cost & 8.0 & 7.0 & 1.14 & -0.24 & 2.87 \\
High cost & 7.2 & 7.0 & 1.03 & -0.21 & 2.93 \\
\hline
\end{tabular}


TABLE 4 Summary statistics for the four asset classes used in the risk-based strategies over the period January 1988-December 2010.

\begin{tabular}{lccccc}
\hline & $\begin{array}{c}\text { Annualized } \\
\text { returns (\%) }\end{array}$ & $\begin{array}{c}\text { Annualized } \\
\text { volatility (\%) }\end{array}$ & $\begin{array}{c}\text { Sharpe } \\
\text { ratio }\end{array}$ & Skewness & Kurtosis \\
\hline Russell 3000 & 9.84 & 16.04 & 0.61 & -0.95 & 2.69 \\
GSCl & 5.29 & 20.28 & 0.26 & -0.09 & 2.27 \\
USA Corporate & 8.94 & 5.69 & 1.57 & 0.25 & 2.46 \\
USA 10Y Gov & 7.81 & 7.78 & 1.00 & 0.07 & 0.91 \\
\hline
\end{tabular}

FIGURE 3 Average capital allocations of risk-based strategies to the four asset classes over the period January 1988-December 2010.

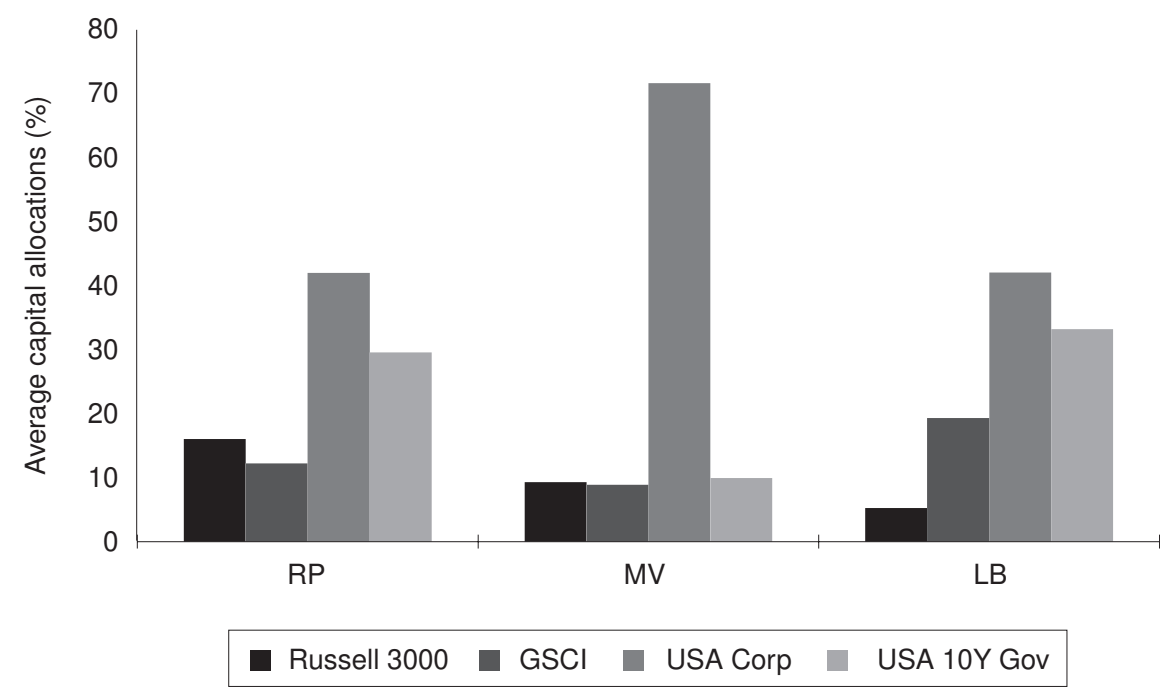

terms of fractional risk contributions, which are discussed in Goldberg et al (2010). The fractional risk contribution of asset class $n$ to portfolio volatility is given by

$$
\mathrm{RC}_{n}=\frac{w_{n}}{\sigma} \frac{\partial \sigma}{\partial w_{n}},
$$

where $\sigma$ is the risk of the portfolio. Then, $\sum_{n=1}^{N} \mathrm{RC}_{n}=1$ and

$$
\mathrm{RDI}=\frac{\left(\sum_{n=1}^{N} \mathrm{RC}_{n}^{2}\right)-1 / N}{1-1 / N}
$$

is the analog to HHI. 
FIGURE 4 Average concentration risk over the period January 1988-December 2010.

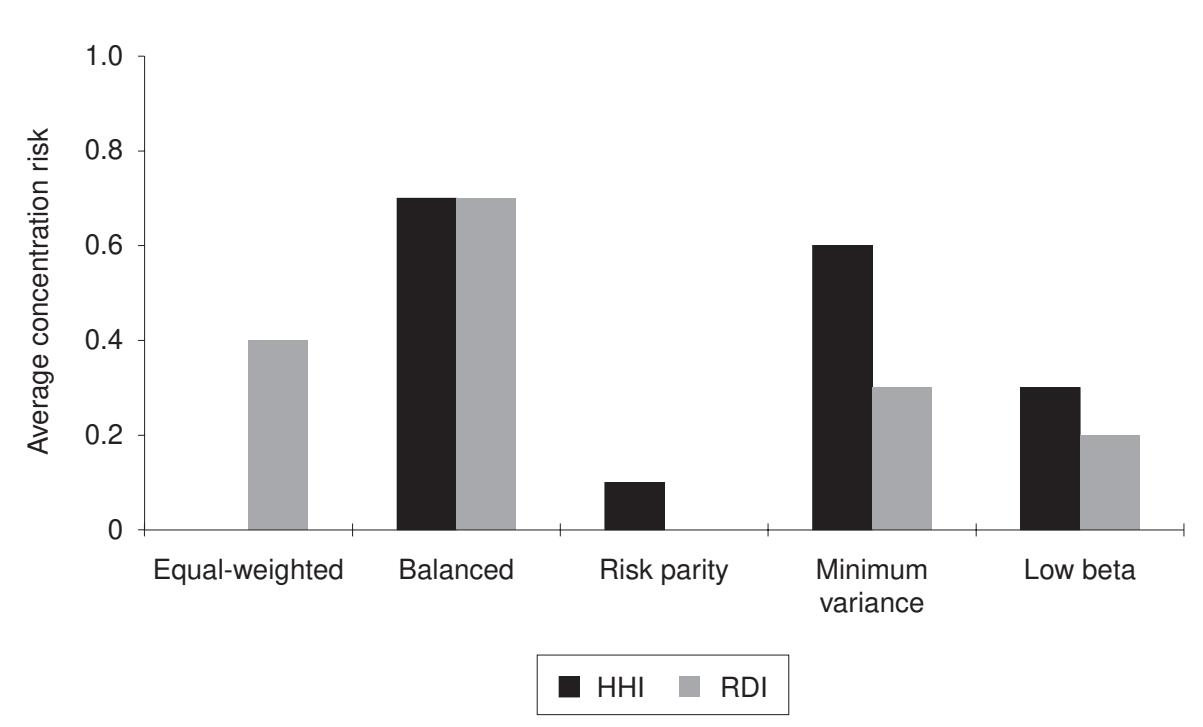

In this paper, we base strategies on the volatility of asset classes rather than their risk contributions. This amounts to the tacit assumption that correlations between pairs of asset classes are zero. Equation (6.3) is a simplified risk diversification index (RDI) that takes that assumption into account:

$$
\mathrm{RDI}=\frac{\left(\sum_{n=1}^{N} w_{n}^{4} \sigma_{n}^{4}\right) /\left(\sum_{n=1}^{N} w_{n}^{2} \sigma_{n}^{2}\right)^{2}-1 / N}{1-1 / N} .
$$

Figure 4 shows the Herfindahl-Hirschman and risk diversification indices for the strategies in our study. Only the risk parity strategy is diversified in both capital and risk.

\section{CONCLUSION}

Consistent with the large empirical literature on low-risk investing, we found that three risk-only strategies outperformed an equally weighted strategy and a balanced strategy over the period from January 1988 to December 2010. There is no consensus about what drives the abnormal returns that risk-based strategies exhibit in idealized settings, or whether these abnormal returns can reliably transcend the transaction costs.

The empirical study discussed in this paper elucidates some of the properties of risk-based investing. Specifically, we have shown that apparently distinct risk-based 
investment strategies are manifestations of a single effect, turnover and associated transaction costs can be a substantial drag on their return and concentration is an understated source of their risk.

In our study, risk parity outperformed the other strategies, and that may stem from the fact that the risk parity strategy was diversified in both capital and risk weights. Further research into the relationship between these two types of diversification is warranted.

\section{REFERENCES}

Anderson, R. M., Bianchi, S. W., and Goldberg, L. R. (2012). Will my risk parity strategy outperform? Financial Analysts Journal 68(6), 75-93.

Black, F., Jensen, M. C., and Scholes, M. (1972). The capital asset pricing model: some empirical tests. In Studies in the Theory of Capital Markets, Jensen, M. C. (ed.), pp. 79121. Praeger, Westport, CT.

Clarke, R., Silva, H. D., and Thorley, S. (2011). Minimum variance portfolio composition. Journal of Portfolio Management 37(2), 31-45.

Fama, E. F., and French, K. R. (1992). The cross-section of expected stock returns. Journal of Finance 47(2), 427-465.

Fama, E. F., and French, K. R. (2004). The capital asset pricing model: theory and evidence. Journal of Economic Perspectives 18(1), 25-46.

Goldberg, L. R., Hayes, M. Y., Menchero, J., and Mitra, I. (2010). Extreme risk analysis. Journal of Performance Measurement 14(3), 17-30.

Markowitz, H. (1952). Portfolio selection. Journal of Finance 8(1), 77-91.

Scherer, B. (2011). A note on the returns from minimum variance investing. Journal of Empirical Finance 18(4), 652-660. 